\title{
THE EFFECTS OF ANTIMICROBIAL AGENTS UPON CHOLINE DEGRADATION IN THE INTESTINAL TRACT
}

\author{
By J. DE LA HUERGA, PAUL GYORGY, SHELDON WALDSTEIN, RICARDO KATZ, \\ AND HANS POPPER \\ (From the Hektoen Institute for Medical Research of the Cook County Hospital, Department \\ of Pathology of Northwestern University Medical School, Chicago, Ill. and Department \\ of Pediatrics, School of Medicine, University of Pennsylvania, Philadelphia, Pa.):
}

(Submitted for publication April 11, 1953; accepted July 21, 1953)

\section{INTRODUCTION}

A variety of intestinal bacteria have been shown to be capable of degrading choline to trimethylamine (1-3) which is readily absorbed from the intestine and excreted in the urine mainly as trimethylamine oxide. When a relatively large amount of choline is ingested by normal persons, about 60 per cent appears in the urine as total trimethylamines (TTMA), mostly within 24 hours (3).

Part of the evidence gathered to establish this phenomenon was that, following ingestion of choline with aureomycin, much less TTMA than usual were excreted $(3,4)$. Further experiments were undertaken to elaborate upon the inhibition of TTMA formation from choline by antimicrobial agents.

Several antimicrobial agents were administered in single therapeutic doses simultaneously with choline to determine whether they exhibited an effect similar to aureomycin. The period of suppression of bacterial degradation of choline was explored by allowing a time interval between the ingestion of the antibiotics and the choline. The development of bacterial resistance to the suppressive effect was studied by the protracted administration of an antibiotic in conjunction with repeated ingestion of choline.

\section{MATERIAL AND METHODS}

Of the 36 subjects used in this study, 26 were patients hospitalized at Cook County Hospital for a variety of causes other than intestinal or hepatic disease, and 10 were young, healthy physicians.

Choline was given orally in the form of bicarbonate 1 in amounts containing $4 \mathrm{Gm}$. choline base ( $460 \mathrm{mg}$. N) with the exception of the four normal subjects who received $5.4 \mathrm{Gm}$. choline chloride $(540 \mathrm{mg}$. $\mathrm{N}$ ). This is twice the

1 Thanks are due to Commercial Solvents Corporation for the generous supply of choline bicarbonate syrup. amount of choline used in previous studies (3). This large dose of choline was chosen since the use of a larger dose would give a better indication of the depression of trimethylamine formation by the antimicrobial agents. Following this, the urine was collected for the first and second 24 hours in separate containers using hydrochloric acid as preservative. The 24 to $\mathbf{4 8}$ hour excretions were determined to serve as a check that no unusual delay in TTMA excretion occurred, which might account for low values in the first 24 hours. Urinary TTMA were determined by the reduction-aeration-reineckate method reported previously (3) and the results are expressed in mg. TTMA N. At least one week was allowed to elapse between the first (control) determination and the one in which an antimicrobial agent was given together with choline. This interval was chosen to make certain that the TTMA excretion had returned to the small basal level (5 to $15 \mathrm{mg}$. TTMA N per 24 hours), resulting probably from the degradation of dietary choline. In the four instances in which one subject was used for two tests, at least two weeks elapsed between determinations.

In the single experiments, the following antimicrobial agents were given orally : aureomycin ( $500 \mathrm{mg}$.) ; terramycin (500 mg.); penicillin O (600,000 units); dibenzylethylenediamine penicillin (DBED-penicillin) $(600,000$ and 25,000 units); sulfaphthalidine $(4 \mathrm{Gm}$.); and gantrisin $(4 \mathrm{Gm}$.). In the protracted experiments, DBED-penicillin was given in amounts of 200,000 units with choline and, on the days in between, 100,000 units were given twice daily. In similar experiments one $\mathrm{Gm}$. of aureomycin was given daily for seven days. Aureomycin was also given intravenously in the form of $500 \mathrm{mg}$. in saline the evening before the administration and the same dose the next morning when the test dose of choline was given orally.

From terramycin, penicillin O, DBED-penicillin, sulfaphthalidine and gantrisin, no trimethylamine was recovered in vitro when the method used in the urines was applied. Aureomycin produced in vitro traces of trimethylamine, but failed to produce any increase in urinary TTMA excretion after oral administration in a normal person.

\section{RESULTS}

The 32 subjects, who received $4 \mathrm{Gm}$. choline, excreted from 220 to $315 \mathrm{mg}$. TTMA N within the first 24 hours after ingestion of the choline, with a mean excretion of $262 \mathrm{mg}$. Only in three instances 


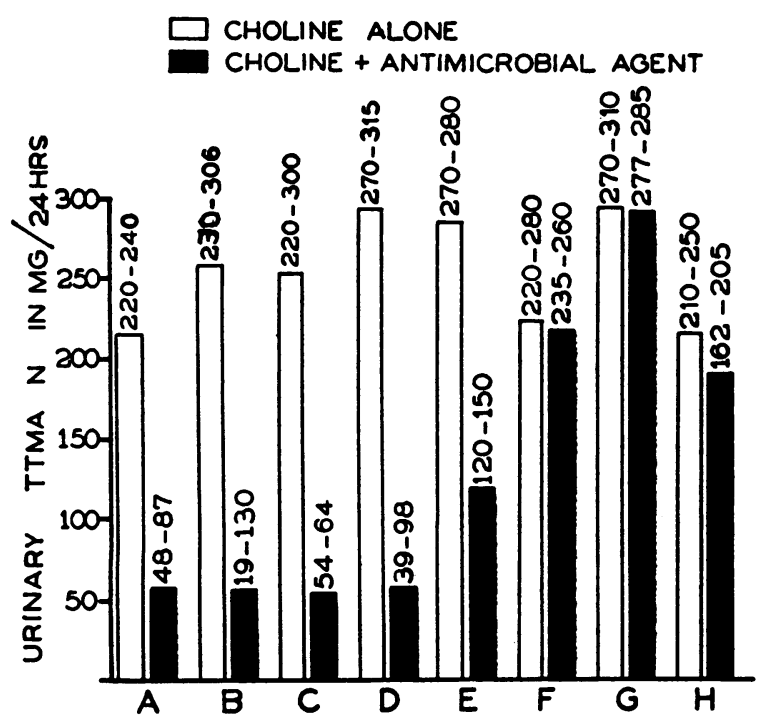

Fig. 1. Urinary Excretion of Total TrmmethylAMines After the Intake of $4 \mathrm{GM}$. Choline Base (460 Mg. N) with and without Simultaneous Administration of an ANti-Microbial Agent
A. Oral, $500 \mathrm{mg}$. aureomycin.
B. Oral, $500 \mathrm{mg}$. terramycin.
C. Oral, 600,000 units penicillin 0 .
D. Oral, 600,000 units DBED-penicillin.
E. Oral, 25,000 units DBED-penicillin.
F. Oral, $4 \mathrm{Gm}$. sulfaphthalidine.
G. Oral, $4 \mathrm{Gm}$. gantrisin.
$\mathrm{H}$. Intravenous, $1 \mathrm{Gm}$. aureomycin.

of the entire study was the 24 to 48 hours excretion significant. The average urinary excretion of TTMA $\mathrm{N}$ in this period was $34 \mathrm{mg}$. (about 7 per cent of the $460 \mathrm{mg}$. of choline $\mathrm{N}$ fed) for the controls and tests. Since one-third to one-half of this amount is basal excretion, only 3 to 5 per cent of the choline nitrogen fed was excreted in the second 24 hours urine collection, and this small amount has been disregarded in the consideration of the results.

\section{Effect of antimicrobial agents fed simultaneously with choline}

Three persons, given aureomycin together with choline, excreted an average of $68 \mathrm{mg}$. of TTMA $\mathrm{N}$ compared to $233 \mathrm{mg}$. when choline was fed alone (Figure 1A). Following administration of terramycin to three subjects, the mean TTMA excretion was $64 \mathrm{mg}$. $\mathrm{N}$ in contrast to $270 \mathrm{mg}$. $\mathrm{N}$ after feeding choline alone (Figure 1B). In the two subjects, each of whom received penicillin $\mathrm{O}$ together with choline, the mean control TTMA N excretion of $260 \mathrm{mg}$. was reduced to $59 \mathrm{mg}$. (Fig- ure 1C). DBED-penicillin, given to seven subjects in doses of 600,000 units together with choline, reduced the TTMA excretion from an average of $286 \mathrm{mg}$. to $65 \mathrm{mg}$. N (Figure 1D). Following the administration of 25,000 units of DBED-penicillin to two subjects, the mean TTMA $\mathrm{N}$ excretion of $280 \mathrm{mg}$. was reduced to $136 \mathrm{mg}$. (Figure 1E). Sulfaphthalidine (Figure $1 \mathrm{~F}$ ) and gantrisin (Figure $1 \mathrm{G}$ ), both given in amounts of $4 \mathrm{Gm}$. to three patients, did not significantly alter the average TTMA excretion following ingestion of choline. Intravenous aureomycin also had hardly any effect in three subjects (Figure 1H).

Five subjects received 600,000 units of DBEDpenicillin 24 hours before the standard dose of choline. Urine collection was begun with the ingestion of the choline. The average control TTMA N excretion was $265 \mathrm{mg}$. whereas after penicillin administration the excretion was 210 mg. (Figure 2).

\section{Prolonged administration of antibiotic agent}

In five persons the TTMA excretion, after administration of choline alone and of choline with 200,000 units DBED-penicillin, was determined.

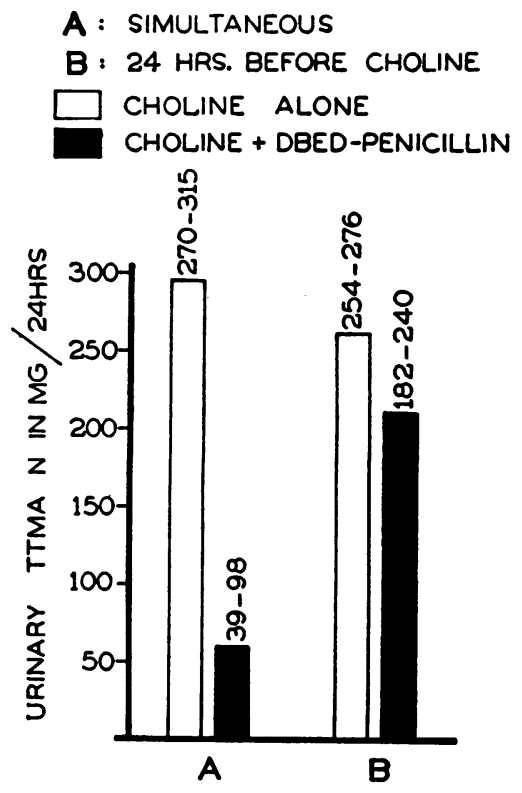

Fig. 2. Mean Urinary Total Trimethylamines of Three Subjects after Administration of $4 \mathrm{Gm}$. Choline Base (460 Mg. N) Alone, Simultaneously or 24 Hours after Administration of 600,000 Units of DBED-PENICILLIN 


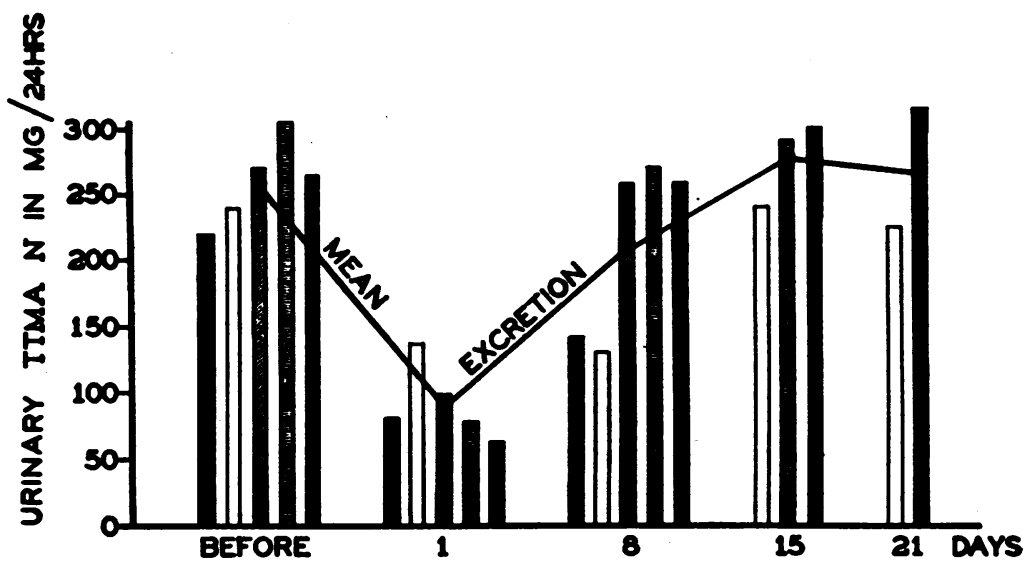

Fig. 3. Urinary Total Trmatethyamines Excretion of Five Subjects Following the Intake of $4 \mathrm{GM}$. OF Choline (460 Mg. N) BEFore AND dURing DaIly Administration of 200,000 Units of DBED-Penicillin For SeVEral. WeEks

Subsequently, they were fed daily doses of 100,000 units twice a day of DBED-penicillin for one to three weeks. At weekly intervals, a standard dose of choline was given and the urinary TTMA were determined. The penicillin administration was not interrupted during the period of the tests with choline. In these persons, the mean control TTMA $\mathrm{N}$ excretion was $263 \mathrm{mg}$. The excretion after the initial dose of penicillin was significantly reduced ( $89 \mathrm{mg} . \mathrm{N})$; after the first week of daily administration of penicillin an almost complete return ( $220 \mathrm{mg}$. N) to the control value was observed. In the three persons who were continued on penicillin for two weeks, and in the two who were continued on penicillin for three weeks, the values had returned to control levels (278 and $270 \mathrm{mg}$. TTMA $\mathrm{N}$, respectively) (Figure 3).

Four normal subjects were given aureomycin, one $\mathrm{Gm}$. a day continuously for seven days. Choline chloride, $5.4 \mathrm{Gm}$. a day, was given on the first, the second, and the seventh day. A decrease of urinary TTMA excretion of approximately 50 per cent of the control level was noted following administration of aureomycin for one day, but the TTMA excretion returned to control levels by the seventh day.

\section{DISCUSSION}

The antibiotic agents studied are capable of inhibiting significantly the degradation of choline to trimethylamine by intestinal bacteria. This is concluded from the reduction in urinary excretion of TTMA from about 50 to 60 per cent of the choline $\mathrm{N}$ fed to only 12 to 16 per cent following the oral ingestion of aureomycin, terramycin, penicillin $O$, and DBED-penicillin. This conclusion is based on the previous observations that bacteria did not degrade choline to any other nitrogenous compound other than trimethylamine, that ingested trimethylamine is quantitatively excreted in the urine, and that, in conditions with reduced TTMA excretion, no appreciable amount of choline appeared in the feces. Since the reported effect is produced by antimicrobial agents of different chemical constitution, a chemical action can be excluded. The fact that soluble penicillin $O$ is equally effective in the doses used, as the slightly water-soluble DBED-penicillin, suggests that the inhibition occurs in the upper portion of the small intestine before adsorption of the antibiotic takes place. When aureomycin is given intravenously a small amount is excreted in the bile $(5,6)$ and inhibition of colonic bacteria has been found. Apparently, concentrations sufficient for the purpose of this experiment were not reached, in the time required by this route, that would exert an inhibitory effect. The sulfa drugs tested were ineffective. This observation is surprising in view of the known inhibitory effect of sulfonamides; however, sulfonamides and antibiotics act through different pathways.

The suppressive effect of antibiotics is of short duration. When penicillin in effective doses is given 24 hours before choline, TTMA are ex- 
creted in similar amounts as in the controls, suggesting bacterial recovery within 24 hours. That the inhibitory effect is not continuously exerted is shown by daily feeding of penicillin. The inhibitory effect is demonstrable after four days $(3,4)$. However, within one week, considerable recovery of TTMA excretion occurs, and after two and three weeks of feeding penicillin or aureomycin daily, control amounts of TTMA are excreted after a standard dose of choline. This represents an analogy to the transient effect of antimicrobial agents in improving hepatic coma, an effect which has been noted by some investigators $(7,8)$, and which is lost within a short period. It may well be that toxic amines, possibly responsible for hepatic coma, are formed in the intestine from amino acids, just as the pharmacologically inert trimethylamine is formed, and the antimicrobial agents may temporarily inhibit their formation. After the bacteria become refractory, coma reappears if the hepatic condition has not improved sufficiently in the interim.

At present, it cannot be decided whether the discussed antibiotic effect upon the intestinal choline degradation is of physiological significance. Aureomycin, terramycin, and penicillin have shown a definite delaying effect on experimental dietary necrosis and cirrhosis $(9,10,11)$. In the short-term experiments, dealing with fatty liver and hemorrhagic cortical necrosis of the kidney, the beneficial effect of antibiotics may be related to the inhibition of intestinal degradation of choline (12). On the other hand, it is difficult to explain the prolonged effect of antibiotics, such as aureomycin and penicillin, on experimental dietary cirrhosis and necrosis of the liver, when one considers their apparently only transient effect on the intestinal flora, as exemplified by the intestinal degradation of choline.

\section{SUM MARY}

Oral aureomycin, terramycin, penicillin $O$, and dibenzylethylenediamine penicillin suppress the urinary trimethylamines excretion after simultaneous ingestion of a test dose of choline. In view of previous observations, this can be considered a suppression of intestinal degradation of choline to trimethylamine by intestinal bacteria.

Intravenous aureomycin and oral sulfaphthalidine and gantrisin are ineffective.
The described antimicrobial effect disappears within 24 hours after the administration of a single dose of penicillin. With continuous administration of pencillin, the antimicrobial effect disappears within one to two weeks indicating refractiveness of the bacteria.

The significance of these findings and the understanding of the effects of antibiotics in hepatic coma and choline metabolism are discussed.

\section{REFERENCES}

1. Cohen, G. N., Nisman, B., and Raynaud, M., Sur la dégradation bacterienne de la choline et de la colamine. Compt. rend. Acad. d. sc., 1947, 225, 647.

2. Dyer, F. E., and Wood, A. J., Action of enterobacteriaceae on choline and related compounds. J. Fisheries Research Board, Canada, 1947, 7, 17.

3. de la Huerga, J., and Popper, H., Urinary excretion of choline metabolites following choline administration in normals and patients with hepatobiliary diseases. J. Clin. Invest., 1951, 30, 463.

4. de la Huerga, J., and Popper, H., Factors influencing choline absorption in the intestinal tract. J. Clin. Invest., 1952, 31, 598.

5. Zaslow, J., Hewlett, T. H., and Lorry, R. W., The excretion and concentration of aureomycin in the abnormal human biliary tract. Part I. Gallbladder. Gastroenterology, 1950, 16, 475.

6. Zaslow, J., Hewlett, T. H., and Goldsmith, R., The excretion and concentration of aureomycin in the abnormal human biliary tract. Part II. Hepatic bile. Gastroenterology, 1950, 16, 479.

7. Farquhar, J. D., Stokes, J., Jr., Whitlock, C. M., Jr., Bluemle, L. W., Jr., and Gambescia, J. M., Studies on the use of aureomycin in hepatic disease. III. A note on aureomycin therapy in hepatic coma. Am. J. M. Sc., 1950, 220, 166.

8. Ducci, H., and Katz, R., Cortisone, ACTH and antibiotics in fulminant hepatitis. Gastroenterology, 1952, 21, 357.

9. György, P., Stokes, J., Jr., Smith, W. H., and Goldblatt, H., Studies on the use of aureomycin in hepatic disease. II. The effect of aureomycin on experimental dietary hepatic necrosis. Am. J. M. Sc., 1950, 220, 6.

10. György, P., Stokes, J., Jr., Goldblatt, H., and Popper, $H$., Antimicrobial agents in the prevention of dietary hepatic injury (necrosis, cirrhosis) in rats. J. Exper. Med., 1951, 93, 513.

11. György, P., Stokes, J., Jr., and Goldblatt, H., Antimicrobial agents in the prevention of experimental dietary injury of the liver. Tr. A. Am. Physicians, 1951, 64, 289.

12. Baxter, J. H., and Campbell, H., Effects of aureomycin on renal lesions, liver lipid, and tissue choline in choline deficiency. Proc. Soc. Exper. Biol. \& Med., 1952, 80, 415. 